\title{
Correction to: Effect of foliar applications of silicon and titanium dioxide nanoparticles on growth, oxidative stress, and cadmium accumulation by rice (Oryza sativa)
}

\author{
Muhammad Rizwan ${ }^{1}$ (D) . Shafaqat Ali ${ }^{1}$. Muhammad Zia ur Rehman ${ }^{2} \cdot$ Sumaira Malik $^{1} \cdot$ Muhammad Adrees $^{1}$. \\ Muhammad Farooq Qayyum ${ }^{3}$. Saud A. Alamri ${ }^{4}$. Mohammed Nasser Alyemeni ${ }^{4}$. Parvaiz Ahmad ${ }^{4,5}$
}

Published online: 22 April 2019

(c) Franciszek Górski Institute of Plant Physiology, Polish Academy of Sciences, Kraków 2019

\section{Correction to: Acta Physiologiae Plantarum (2019) 41:35 https://doi.org/10.1007/s11738-019-2828-7}

The original version of this article unfortunately contained a mistake. The Research Group number information in the Acknowledgements section was incorrect. The correct information is given below.

Acknowledgements The authors would also like to extend their sincere appreciation to the Deanship of Scientific
Research at King Saud University for its funding to the Research Group number (RGP-199).

Publisher's Note Springer Nature remains neutral with regard to jurisdictional claims in published maps and institutional affiliations.

The original article can be found online at https://doi.org/10.1007/ s11738-019-2828-7.

Muhammad Rizwan

mrazi1532@yahoo.com

1 Department of Environmental Sciences and Engineering, Government College University, Allama Iqbal Road, 38000 Faisalabad, Pakistan

2 Institute of Soil and Environmental Sciences, University of Agriculture, 38040 Faisalabad, Pakistan

3 Department of Soil Science, Faculty of Agricultural Sciences and Technology Bahauddin, Zakariya University, Multan, Pakistan

4 Department of Botany and Microbiology, College of Science, King Saud University, Riyadh, Saudi Arabia

5 Department of Botany, S.P. College, Maulana Azad Road, Srinagar, Jammu and Kashmir 190001, India 